\title{
Deleterious Oral Habits in Preschool Children with Sensory Processing Disorder: An Association Study
}

\author{
Mylena Helen Silva Santos ${ }^{1}$, Manuel de Oliveira Dantas Filho ${ }^{2}$, Maria da Conceição de Barros Correia ${ }^{1}$, Cláudia \\ Wanderley de Barros Correia ${ }^{1}$, Valter Romão de Souza Júnior ${ }^{1}$, Yuri Victor de Medeiros Martins ${ }^{3}$, Alexandre \\ Policarpo da Silva ${ }^{3}$, Guilherme Soares Gomes da Silva ${ }^{1}$, Niedje Siqueira de Lima ${ }^{1}$ and Luciana de Barros \\ Correia Fontes ${ }^{1^{*}}$
}

${ }^{1}$ Federal University of Pernambuco, Brazil

${ }^{2}$ State University of Paraiba, Brazil

${ }^{3}$ Federal University of Rio Grande do Norte, Brazil

Submission: February 02, 2018; Published: June 05, 2018

*Corresponding author: Luciana de Barros Correia Fontes, Federal University of Pernambuco, Pernambuco, Brazil, Email: lu.bc.f@hotmail.com

\begin{abstract}
Objective: To determine the frequency of deleterious oral habits in preschool children with or without sensory processing disorders.

Methods: Cross-sectional study with descriptive and analytical data analysis developed as part of a larger project from 2014 to 2016, in public day care centers in the city of Campina Grande, State of Paraíba, in the Northeast of Brazil. In the statistical analysis a margin of error of $5 \%$ was adopted. The collection occurred through the interview to the responsible ones and of the physical examination of the preschool children at age 2-6 with the registration in standardized file to the study. The variables investigated included age, gender, diagnosis and type of sensory integration disorder and the presence and classification of deleterious oral habits.
\end{abstract}

Results: for the 374 children investigated, mean age was 4.1 years, $59.9 \%$ of males and distributed in a case group and a control group. Of these, $24.9 \%$ had sensory processing disorder; $52.7 \%$ sensory-based motor disorders, $37.6 \%$ sensory modulation disorders and $9.7 \%$ sensory discrimination disorders. In the case group herein, $77.4 \%$ of the preschoolers used some kind of medication directed to the child's treatment for a better development and school performance; particularly language and socialization. The deleterious oral habits occurred in $61.8 \%$ of the children evaluated for both groups. There was a significant difference between the presence of sensory processing disorder, nocturnal bruxism $(\mathrm{p}<0.01)$ and onychophagia $(\mathrm{p}<0.05)$.

Conclusion: More than half of the preschoolers had deleterious oral habits, and there was found an association between nocturnal bruxism and onychophagia when compared to preschoolers with or without disorder in sensory processing.

Keywords: Sensory disorders; Preschool; Sleep bruxism

\section{Introduction}

Learning is understood as a complex and dynamic process, structured from a motor and perceptive act, in which information is initially captured from the environment and goes through continuous processing with successive levels of elaboration from the capture of the sensorial characteristics, followed by the interpretation of the meaning until the response is issued [1].

In this perspective, learning depends on the integrity of sensory processing that is the individual's ability to receive sensory information from the environment and movements of his body, to process and integrate the different sensory modalities in the central nervous system and to use them for adaptive responses. In the presence of sensory processing difficulties, there is a deficit in the planning and production of behavior and/or movement, which may trigger motor performance impairments, difficulties in organizing and maintaining attention, as well as difficulties in school learning process [2]. Mouth habits are defined as the result of the repetition of an act with a certain purpose, becoming with time resistant to change. Generally, at first it is conscious; nevertheless, with the habit acquired by the repetition of acts, it becomes unconscious [3].

Deleterious oral or oral habits are highly related to changes in structures and functions associated with the Stomatognathic System (SS), such as: breathing, chewing, sucking, swallowing and phonoarticulation [4]. The degree of functional deviations provided by habits depends on the triad consisting of intensity, 
frequency and duration. There is, in addition, an association between deleterious oral habits, emotional tension. These are added to the influence of individual predisposition, age, nutritional conditions and general health [5]. It is also recognized that there is a compensatory mechanism related to deleterious oral habits; with alterations in the movements associated with the physiology of the SS and that abnormal sensorimotor integration may be related to movement disorders [6].

Some variables have been reported as possible etiological factors of deleterious oral habits; among them psychological problems, environmental (jealousy, need for attention) and even eating disorder [7]. Morphological and neurophysiopathological factors are also considered, with the production of exacerbated and/or involuntary or mandibular movements associated with disorders with loco motor behaviors [8]. Sensory processing disorder is defined as the presence of a change in detecting, modulating, interpreting or responding to sensory stimulus, previously described in the literature as sensory integration dysfunction [9]. It is a disorder presented by a heterogeneous group of children characterized by the varied experiences of limitations in the participation and accomplishment of the activities. Such a condition can lead to damages associated with social skills, postural control, motor coordination, use and handling of objects, as well as performance in daily life activities and playing immaturity [10].

Based on the Ayres studies, several taxonomies and classifications of behavioral subtypes related to sensory processing disorder were used over time. However, one of the most recent diagnostic approaches classifies the sensory processing disorder in: sensory modulation disorders, sensory discrimination disorders and sensory-based motor disorders, explained in the sequence $[7,9,11,12]$.

Sensory modulation disorders are characterized by difficulty in regulating degree, intensity and nature of responses to sensory stimuli, and can be classified into:

a) Sensory hyporesponsiveness, with poor reaction to relevant stimuli of the environment, such as pain, movements or odors;

b) Sensorial hyperresponsiveness, with a greater tendency to orient and respond to certain stimuli, such as touch, movement, lights, sounds, presenting, for example, aversive responses or movement intolerance, with reaction of nausea, nausea and of minimal stimuli;

c) Sensorial search, with constant demand for intense stimuli, be it vestibular, proprioceptive and others. Sensory discrimination disorders are related to the difficulties in interpreting the quality or the singularity of each stimulus, to perceive their differences and similarities, being able to present different degrees of difficulties in the diverse sensorial modalities, such as visual, tactile, auditory, vestibular, proprioceptive, gustatory and olfactory.
Sensory-based motor disorders are characterized by individuals with difficulties in integrating their own body information and moving efficiently in the environment. The most common problems are:

a) Postural disorder with difficulty stabilizing the body during movement or rectify the posture when requested by the movement;

b) Dyspraxia, with difficulty in idealizing, creating, initiating, planning, sequencing, modifying and performing actions.

There are information gaps in the literature on the oral health conditions of children with sensory processing disorders. The present study had as objective to determine the frequency of deleterious oral habits in preschool children with or without sensory processing disorders and to verify the existence of an association between the frequency of these habits and the presence of sensory processing disorder.

\section{Methods}

This work represents a part of the continuity of a research project developed in the city of Campina Grande, State of Paraíba, Notheast of Brazil, between the years 2014 and 2016. It is a transversal study, with descriptive and inferential analysis of the data. In the sample calculation, a margin of error of $5 \%$, a $\beta$ of 0.20 and a prevalence of speech or language disorders estimated at $24.6 \%$ were adopted. For the present study, the inclusion criteria included preschool children between the ages of two and six, of both sexes, regularly enrolled in early childhood education in 2014, with complete deciduous dentition. The study participants were divided into two groups: the case, for preschoolers who had symptoms identified by the school or diagnosis of some sensory processing disorder and control, absence of symptoms or diagnosis for such disorders.

Patients diagnosed with severe neurological sequelae, syndromes, mental deficit, hearing impairment, with one or more permanent teeth bursting were excluded. The variables investigated included gender, age, presence and classification of the disorder in sensory processing and the use or not of regular medication, besides the history of deleterious oral habit and its classification. Data collection for this work occurred between December 2014 and February 2015, in the classrooms themselves and in the form of interviews with the parents or guardians and with the teachers; these for the symptoms or diagnosis of sensory processing disorder.

For the symptoms of sensory processing disorder, the study by Dunn [12] \& Miller et al. [13] was considered and for the evaluation of deleterious oral habits of Melo \& Pontes [14]. During the collection, the participation of the Occupational Therapist who accompanied some children from the day care center, helped with the application of the questionnaire and evaluation of the sensorial profile. There was a comparison with records in day care 
centers where the preschoolers were evaluated. Data analysis was performed using descriptive and inferential statistics techniques, using a margin of error and using SPSS (StatisticalPackage for the SocialSciences) software, version 16.

This work respected the principles of the Universal Declaration on Bioethics and Human Rights. Data collection took place with the prior approval of the UEPB's Research Ethics Committee. When the treatment needs were identified, in the scope of occupational therapy, phonoaudiology and dentistry, the preschool children were referred for treatment in the public services area.

\section{Results}

For a total of 374 preschoolers, 93 (24.9\%) of the children had symptoms or the diagnosis of some disorder in sensory processing. Considering the total sample, $59.9 \%$ of the students were male. Analyzing exclusively the case group, 64 (68.8\%) of the students were male. The mean age of all subjects in the sample was $4.1 \pm 0.8$ years. In the preschool children within the group, 4.2 \pm 0.3 years, and in the control group $3.8 \pm 0.2$ years.

Table 1: Distribution of the preschool children according to gender, age, sensory processing disorders and deleterious oral habits.

\begin{tabular}{|c|c|c|}
\hline Variable & N & \% \\
\hline Total & 374 & 100,0 \\
\hline \multicolumn{3}{|c|}{ Gender } \\
\hline Male & 224 & 59.9 \\
\hline Female & 150 & 40.1 \\
\hline Age (years) & 62 & 16.6 \\
\hline 2 & 65 & 17.4 \\
\hline 3 & 144 & 38.5 \\
\hline 4 & 103 & 27.5 \\
\hline 5 & 93 & 24.9 \\
\hline \multicolumn{2}{|c|}{ Sensory Processing Disorder } \\
\hline Yes & 281 & 75.1 \\
\hline No & 257 & 68.7 \\
\hline \multicolumn{2}{|c|}{ Deleterious Oral Habits } \\
\hline Yes & 117 & 31.3 \\
\hline No &
\end{tabular}

Regarding deleterious oral habits, there was mention by parents of $61.8 \%$ of the children considered. In the group, there was a greater report of deleterious habits by parents or guardians (65.6\%), but no statistically significant difference was found ( $\mathrm{p}>0.05)$. The Oral Respiratory ("OR") preschoolers, despite a direct association with the "SS", were counted separately, in the final percentage of individuals with deleterious oral habits. In this way, considering the two groups, we obtained, in decreasing order of frequency: oral breathers (52.9\%), patients with a deleterious habit of pacifier sucking $(41.7 \%)$, nocturnal bruxism (38.9\%), (20.1\%) and onychophagia (20.1\%). There was mention of an association between sucking habits and onychophagia. The percentage of preschoolers with sensory processing disorders were: oral breathers (53.8\%), pacifiers (39.8\%), nocturnal bruxism (57\%), digital suction (18.3\% \%) and onychophagia (28\%). (Table 1) shows the distribution of preschool children, according to gender, age and the presence or absence of disorder in sensory processing.

Table 2: Sleep Bruxism and Onychophagia according to case or control groups.

\begin{tabular}{|c|c|c|c|c|c|c|c|}
\hline \multicolumn{8}{|c|}{ Study Groups } \\
\hline \multirow[t]{2}{*}{ Variable } & \multicolumn{2}{|c|}{ Case (TPS) } & \multicolumn{2}{|c|}{ Control } & \multicolumn{2}{|c|}{ Total Group } & \multirow[t]{2}{*}{ P Value } \\
\hline & $\mathbf{N}$ & $\%$ & $\mathbf{N}$ & $\%$ & $\mathbf{n}$ & $\%$ & \\
\hline Total & 93 & 100,0 & 281 & 100,0 & 374 & 100,0 & \\
\hline \multicolumn{8}{|c|}{ Sleep Bruxism } \\
\hline Yes & 90 & 96.8 & 55 & 19.6 & 145 & 38.8 & \multirow{2}{*}{$\begin{array}{l}\mathrm{p}(1)< \\
0,001^{*}\end{array}$} \\
\hline No & 3 & 3.2 & 226 & 80.4 & 229 & 61.2 & \\
\hline \multicolumn{8}{|c|}{ Onycophagia } \\
\hline Yes & 27 & 29 & 48 & 17.1 & 75 & 20.1 & \multirow{2}{*}{$\begin{array}{l}\mathrm{p}(1)< \\
0.005^{*}\end{array}$} \\
\hline No & 66 & 71 & 233 & 82,9 & 299 & 79.9 & \\
\hline
\end{tabular}

$\left.{ }^{*}\right)$ : Statistical Significance Association 5.0\%.

(1): Fisher's Exact Test

For those with the condition, we found a descending order of frequency: sensory-based motor disorders (52.7\%), sensory modulation disorders (37.6\%) and sensory discrimination disorders (9.7\%). Of these, $77.4 \%$ used some type of medicine directed to the treatment of the child, for a better development and school performance; particularly language and socialization. With regard to deleterious oral habits, reports of tooth grinding (nocturnal bruxism) and onychophagia presented a higher frequency in the case group, with a significant difference when compared to the control $(\mathrm{p}<0.01$ and $\mathrm{p}<0.05$, respectively), as can be seen in (Table 2). In the control group, deleterious sucking habits were the most recorded.

\section{Discussion}

There were difficulties in comparing the results obtained in the present study, due to the fact that they were not found in the literature consulted, works directed to students in this age group presenting problems in sensory integration and related to oral health; particularly on deleterious oral habits. This may be due to the fact that although it is not a recent issue, much is still known and clarified about sensory integration and possible disorders.

The instrument of data collection, in the part of the identification of the disorders in the sensory processing, started from classic works, like the one of Dunn $[12,15]$ that evaluates, in a detailed form, the sensory processing, area subdivided into three areas, with specific categories: sensory processing (hearing, vision, movement, touch, multi-sensory and oral), modulation (tonus, body position / movement, activity level, emotional responses and visual stimulus), emotional and social behavior and responses, and thresholds for responses). 
It allows a measurement of the level of severity of the disorder by punctuation and its interpretation, in a simple way; evidencing isolated situations, but in the majority associated with other conditions like hyperactivity and autism. Even if one considers the relative simplicity of the diagnosis of these disorders, one difficulty arises from the fact that the questionnaire is applied to the parents and guardians of the children who were signaled by the school due to difficulties in concentration, language development and socialization. Parents or caregivers could have omitted or minimized the degree of information requested, in the face of the child's learning environment and the possibility of stigma. Despite the inclusive policy adopted in Brazilian educational system, there is a mismatch between the law and the preparation of schools and professionals for this type of student with specifics.

This is due to the lack of knowledge about the possibilities of signaling to the north about the disorder. Also because it is not a complex subject and requires continuous training of a whole team of teachers, auxiliaries and other professionals, to deal adequately with these children, contributing to development, autonomy and quality of life in general. In the context of what has been previously mentioned, Aguiar \& Duarte [16] agree on the need for greater support from government spheres for recycling courses, specialized technical pedagogical assistance, adapted structure of physical space and adequate didactic material. Although it is not a given to compare, it is signaled to do so when finding that almost the third of the children were with some type of disorder of sensory integration in the public day care centers of Campina Grande.

We chose a cross-sectional study, which is relatively easy to conduct, by working the exposure and disease simultaneously and can answer questions about the frequency of the risk factor and the outcome; but it has in its time-frame its limitations to explain what would be the cause and the effect [17]. According to the results obtained in this research, a higher percentage of male preschoolers (59.9\%) presented sensory processing disorders; which agrees with the systematic review of Machado et al. [18]. Most of the students included in the case group used regular medication, but there was a prominence regarding the discontinuity of the therapeutic process with drugs. According to $\mathrm{Wu}$ et al. [19], the discontinuity in the use of these drugs would be translated into results of lower effectiveness for children's development, recognizing that it is still a controversial issue.

Among the deleterious oral habits, reports, significant differences between groups existed for nighttime bruxism or grinding of teeth and for onychophagy or nail gnawing. A possible explanation would be related to the association between sleep patterns and motor activity, since some findings corroborate the idea that a patient with ADHD, a condition related to sensory integration, can have a duration of 24 hours, that is, the symptoms of hyperactivity could remain during sleep, with greater movement in that period.
Others suggest that sleep disturbance caused by the movements performed by the sleeping child could contribute to the daytime symptoms of TADH, with characteristics of excessive sleepiness during the day.

Thus, a more detailed analysis of the relationships between these variables would provide insights to understand the role of sleep in changes in motor activity and, consequently, elucidate the participation of wake / sleep cycle changes in the etiology of this disorder, which could contribute to the development of new ways of treating and improving the quality of life of patients and their families [20]. The distribution of deleterious habits resembles data from the study by Ferreira et al. [20], on the impact of early weaning on the frequency of these habits. This condition was not raised in the present study. It should be noted that many responsible for children were grandparents (32.4\%).

The high frequency of onychophagia and nocturnal bruxism could still be conditioned by the fact that children with SPD have exacerbated oromandibular movements that, associated with the emotional tensions, especially in the learning environment. In this study it was observed that a significant number of the children studied presented SPD and that they are not in an adequate school, considering that they need a differentiated care, this demonstrates the necessity of studies on the SPD so that there is a better inclusion of these children.

\section{Conclusion}

More than half of preschool children presented deleterious oral habits, and there was an association between nocturnal bruxism and onychophagia when compared to students with or without disorder in sensory processing.

\section{References}

1. Guardiola A, Ferreira LTC, Rotta NT (1998) Performance of literacy and cortical brain functions in a sample of first grade students of Porto Alegre, Brazil. Arq Neuropsiquiatr 56(2): 281-288.

2. Momo ARB, Silvestre C, Graciani Z (2011) Development of sensory processing. Temas sobre desenvolvimento 18(103): 111-120.

3. Antunes LDS, Teixeira EC, Gomes IF, Almeida MH, Mendes PP, et al. (2015) Causal Relationship between the Oral Habits, Feeding and Malocclusion in Children Deciduous Teeth. UNOPAR Cient, Ciênc biol Saúde 17(2): 75-80.

4. Johanns CM, Silvério K, Furkim AM, Marchesan I (2011) Is there a relation between harmful oral habits and facial typology and dental occlusion? Rev CEFAC 13(6): 1095-1102.

5. Barbosa CC, Vasquez S, Parada MA, Gonzalez JC, Jackson C, et al. (2019) The relationship of bottle feeding and other sucking behaviors with speech disorder in Patagonian preschoolers. BMC Pediatr 9: 66.

6. Oliveira CBD, Silva PLPD, Forte FDS, Bonan PRF, Batista AUD (2016) Temporomandibular disorders and oral habits in high-school adolescents: a public health issue?. RGO-Revista Gaúcha de Odontologia 64(1): 8-16.

7. Gisfrede TF, Kimura JS, Reyes A, Bassi J, et al. ( 2016) Deleterious oral habits and its consequences in Pediatric Dentistry Revista Brasileira de Odontologia 73(2): 144-149. 
8. Alencar MJS, Martins BMDC, VieiraBN (2014) Relation between bruxism and dopamine. 71(1): 62-66.

9. White BP, Mulligan S, Merrill K, Wright J (2007) An examination of the relationships between motor and process skills and scores on the sensory profile. Am J OccupTher 61(2): 154-160.

10. Shimizu VT, Miranda MC (2012) Sensory processing in children with ADHD: a revision of the literature. Psicopedagogia 29(89): 256-268.

11. Okumura T, Horii A, Kitahara T, Imai T, Uno A, et al. (2015) Somatosensory shift of postural control in dizzypatients. Acta otolaryngologica 135(9): 925-930.

12. Dunn W (1999) Caregiver Questionnaire - Sensory Profile. Sant Antonio, Pearson, TX, USA.

13. Miller LJ, Anzalone ME, Lane SJ, Cermak SA, Osten ET (2007) Concept evolution in sensory integration: A proposed nosology for diagnosis. Am J OccupTher 61(2): 135-140.

14. Melo PED, Pontes JRS (2014) Deleterious oral habits in a group of children from a public school in Sao Paulo city. Revista CEFAC 16(6): 1945-1952.
15. Mattos JC, D'Antino MEF, Cysneiros RM (2015) Translation into brazilian portuguese and cultural adaptation of the Sensory Profile. Psicologia: Teoria e Prática 17(3): 104-120.

16. Aguiar JS, Duarte E (2007) Inclusive education: a study in the physical education field. Rev bras educ espec 11(2): 223-240.

17. Dornelles JLB, Duquia RP (2007) One of the most used epidemiological designs: cross-sectional study. Scientia Medica out dez 17(4): 229-232.

18. Machado ACCDP, Oliveira SRD, Magalhães LDC, Miranda DMD, Bouzada MCF (2017) Sensory processing during childhood in preterm infants: a systematic review. Rev Paul Pediatr 35(1): 92-101.

19. Wu SH, Wang K, Chen Y, Wan Q, Wang F, et al. (2017) Exploratory analysis of early treatment discontinuation and clinical outcomes of patients with attention-deficit/hyperactivitydisorder. Asia Pac Psychiatry 9 (1): 12231

20. Ferreira AA, Barbosa OLC, Barbosa CCN, Brum SC (2016) Children parafunctional habits arising from early weaning and its mpact on the oral cavity. Ortodontia pp. 143-148.

\section{Your next submission with Juniper Publishers} will reach you the below assets

- Quality Editorial service

- Swift Peer Review

- Reprints availability

- E-prints Service

- Manuscript Podcast for convenient understanding

- Global attainment for your research

- Manuscript accessibility in different formats

( Pdf, E-pub, Full Text, Audio)

- Unceasing customer service

Track the below URL for one-step submission https://juniperpublishers.com/online-submission.php 